\title{
A PROPOSAL FOR MODELING AND IMPLEMENTING AN INTEGRATED SYSTEM FOR BRAZILIAN CADASTRES ACCORDING TO ISO 19152:2012 LAND ADMINISTRATION DOMAIN MODEL
}

\author{
Nathalia Rose Silva da Purificação ${ }^{1}$ - ORCID: 0000-0002-8489-1845 \\ Andrea Flávia Tenório Carneiro² - ORCID: 0000-0002-2445-2330 \\ Rui Pedro Julião ${ }^{3}$ - ORCID: 0000-0002-5625-9965 \\ ${ }^{1}$ Universidade Federal de Pernambuco, Programa de Pós-Graduação em Ciências Geodésicas e Tecnologias da \\ Geoinformação, Recife - PE, Brasil. \\ E-mail: nathaliarosesilva@gmail.com \\ ${ }^{2}$ Universidade Federal de Pernambuco, Departamento de Engenharia Cartográfica, Recife - PE, Brasil. \\ E-mail: andreaftenorio@gmail.com \\ ${ }^{3}$ Universidade Nova de Lisboa, CCIS.Nova, Lisboa, Portugal. \\ E-mail: rpj@fcsh.unl.pt
}

Received in $23^{\text {rd }}$ August 2019

Accepted in $04^{\text {th }}$ October 2019

\begin{abstract}
:
This article proposes the modelling and implementation of an integrated system for Brazilian cadastres, based on the standardized model of land administration described in the ISO 19152:2012 LADM. The model was developed from the identification of the essential elements of the urban, the National Rural Cadastre System and the cadastres of public assets of the Secretariat of the Patrimony of the Union. At all stages of this work, free and/or open source software was used to validate this proposal. The results confirm the viability of the application of the concepts proposed by LADM to the Brazilian system of cadastres, allowing the integration between the systems of different institutions. The model is flexible and allows for the inclusion of additional classes according to changing needs of land administration data users. The current form of the model can be regarded as the basic module to be used as a starting point in the structuring of the National System of Management of Territorial Information, which is aimed at the integration of all existing cadastres and land registries in Brazil.
\end{abstract}

Keywords: LADM, ISO 19152: 2012, cadastre, Brazilian cadastre.

How to cite this article: PURIFICAÇÃO, N. R. S.; CARNEIRO, A. F. T.; JULIÃO, R. P. A proposal for modeling and implementing an Integrated system for brazilian cadastres according to iso 19152:2012 land administration domain model. Bulletin of Geodetic Sciences. 25(4): e2019026, 2019. 


\section{Introduction}

The term Land Administration was created by the United Nations Economic Commission for Europe (UNECE,1996) to describe "the processes of recording and disseminating information about ownership, value, and use of land when implementing land management policies". Land administration systems (LAS) essentially involve the characterization of the relations between people and land, linked to rights (of use or ownership) and are, in most countries, influenced by advances in Information and Communication Technology (ICT) (UN-GGIM,2019; Lemmen,2012). According to Williamson et.al (2010), the function of a land administration system (including land registration) is to recognize and document the relationships between people and land based on legal and institutional arrangements and to disseminate this information in order to facilitate efficient land administration.

The Brazilian land administration system comprises land registries and cadastres. The rural cadastre is a Federal responsibility, while the urban cadastre is a Municipal responsibility, although there is no specific legislation for the civil case. The public lands of the Union are registered by the Federal Property Management Office (SPU), and the public lands of the States by the State Land Institutes. Thus, the establishment of standards for modelling the land administration system is a challenge for a country with continental dimensions such as Brazil, which has a great diversity of legal, administrative, economic, and cultural systems, that vary by region or even by municipalities (Carneiro, 2003).

Land administration in Brazil is thus regarded as fragmented, and there is a need for integration across the various systems. This paper seeks to explore the possibility of such integration and improvement. In recent years, institutions such as the National Institute for Colonization and Agrarian Reform (INCRA) and the Federal Revenue of Brazil (RFB) have implemented systems to improve the integration of land administration databases in order to provide institutions and citizens with more accurate and reliable information. One such initiative is the implementation of the National Cadastre of Rural Property (Cadastro Nacional de Imóveis Rurais - CNIR), which was initiated in 2015. The SINTER is another initiative aimed at improving this integration.

This paper seeks to investigate the viability of integrating the Land Administration Domain Model (LADM) outlined in ISO 19152: 2012 for Brazilian cadastres of urban areas (Santos, 2012), for cadastre of public properties (Frederico, 2014) and the cadastre of rural properties in the National Rural Cadastre System (Purificação e Carneiro, 2017). The ISO 19152: 2012 LADM allows for more efficient land administration through an open and flexible model, which allows for the association of new classes and attributes as necessary.

\section{Literature review}

This section describes the elements of the Land Administration Domain Model (LADM) provided in ISO 19152:2012. It also presents an overview of research regarding the application of this model and its implementation in different systems. The description of Brazilian cadastres according to LADM is highlighted, since the objective of this research is to propose the its integration.

\subsection{ISO 19152: 2012 - Land Administration Domain Model}

According to ISO 19.152:2012 the Land Administration Domain Model (LADM) is a standardized model of land administration that has two main objectives (ISO, 2012):

1. to provie an extensible basis for the development and refinement of efficient and effective land 
administration systems, based on a Model Driven Architecture (MDA), and

2. to enable involved parties, both within one country and between different countries, to communicate, based on the shared vocabulary (that is, an ontology), implied by the model.

According to Lemmen, Oosterom and Bennett (2015), the approach based on MDA allows local details to be added to the conceptual model, offering full customization. Besides, the use of standards helps to avoid inconsistencies between data and facilitates the exchange of information between different data sources and institutions.

The ISO 19152: 2012 LADM considers the fundamental concept of the cadastre, describing the relations between people and lands through rights, restrictions and responsibilities. In Figure 1 three basic packages are presented that can be used to represent the existing relations between these elements (Party, Administrative and Spatial Unit) as well as a subpackage referring to the geometric representation of the spatial units (for Surveying and Representation).

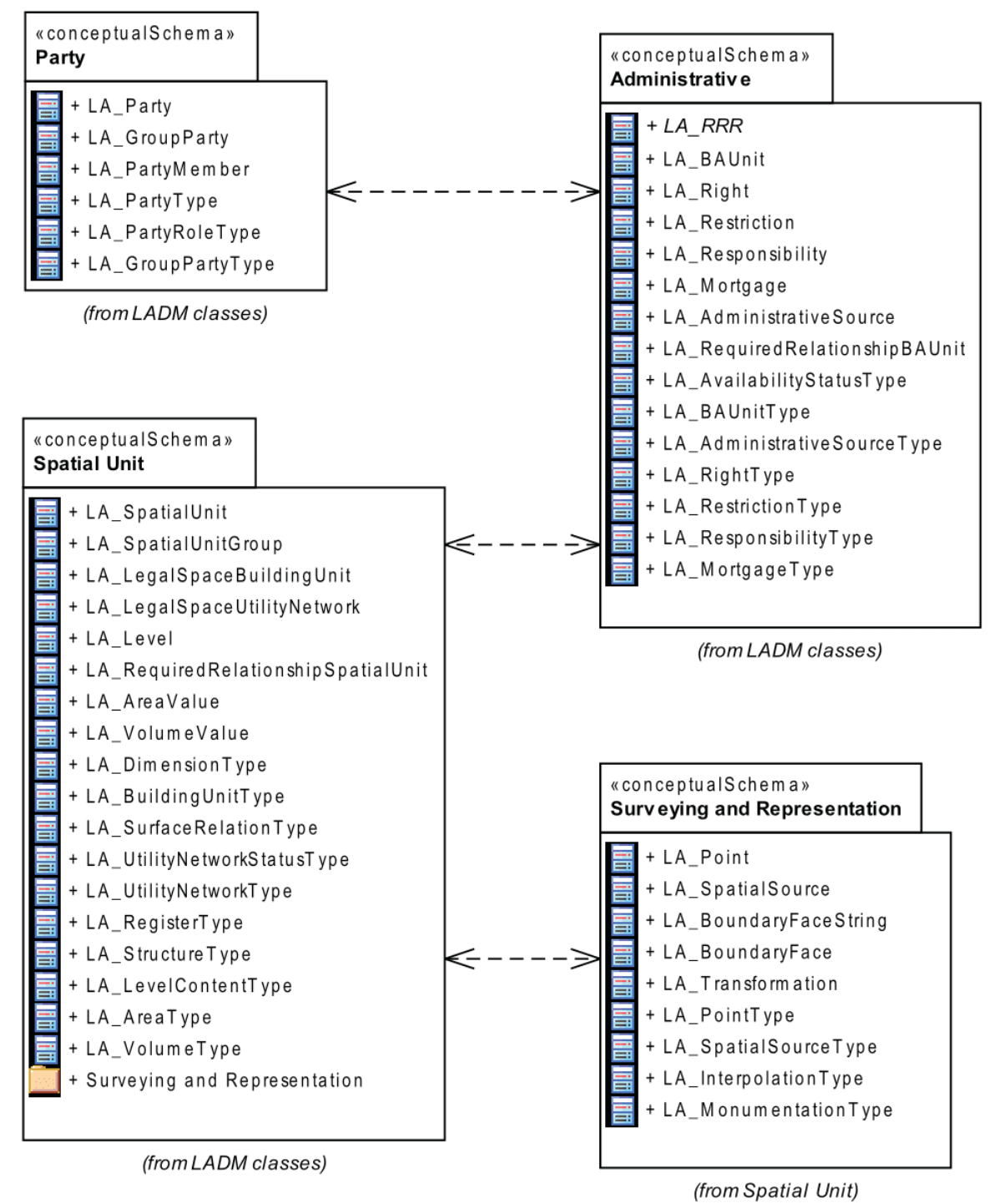

Figure 1: LADM packages and subpackages with their respective classes. Source: ISO/FDIS 19.152 (2012).

Lemmen et. al. (2012) list the requirements for LADM and describes its impacts. According to the authors, the model is based on user needs and should be as simple as possible in order to be useful in practice. The LADM requirements are a continuum of rights to the land (Rights, Restrictions, Responsibilities), a continuum of land use 
right claimants (Party), a continuum of spatial units (land areas or water areas - Spatial Units), and, if necessary, a basic administrative unit (BAUnit).

It is also necessary to describe the methods of data acquisition with support for the inclusion of original survey documents. Furthermore, it is necessary to account for aspects such as transparency, the maintenance of the data history, the use by different organizations, the maintenance of data at the source from a Database Management System (DBMS), the existence of standards, a single reference system, unique identifiers for parcels, and data quality assurance.

\subsection{The LADM: design and developments}

Paulsson and Paasch (2015) provided an overview of research concerning the development and implementation of the LADM. The authors have noticed that LADM research has covered a number of topics ranging from more legislative aspects, about terminology and rights, to data management and visualization. Although LADM describes relations in land based in legislation and informal rights, they have noted a tendency in LADM research to focus on technical issues rather than on more legal ones. Many publications also describe LADM more in general than focusing on and analysing specific aspects.

Research published since 2000 deals with the improvement of cadastral systems from two main points: the need to provide descriptions of relations in land in a structured and standardized way and the technical issues related to these implementations.

The technical aspects have been addressed, for example, by Van Oosterom and Lemmen (2002) and van Oosterom et. al. (2006). Van Oosterom and Lemmen (2002) analyses the impact of the Geo-ICT developments, such as information system modelling standards, database technology, positioning systems, Internet development, wireless communication and acceptance of geometry standards within general ICT tools, on cadastral systems. Van Oosterom et. al. (2006) presented a first exploration on 4D Cadastre. For them next to the spatial (3D) aspect of rights and restrictions the temporal aspect, the fourth dimension of interests in real estate, is an important aspect of cadastral registration. Comert and Alkan (2004) and Alkan and Comert (2010) presented a temporal geographic information system (TGIS) designed and developed for Turkey. This theme was most recently addressed by Doner and Biyik (2013), Aydinoglu and Inan (2014) and Polat et. al. (2018), that apply LADM for modelling 3D/4D cadastre situations in Turkey.

From 2012 on, several publications dealt with the concepts and structures of LADM, but Van Oosteroom and Lemmen (2015) explain that the design process of LADM took place in an incremental approach with continuous expert reviewing from 2002 to 2006 within the International Federation of Surveyors. Then a design and development process for international standards was followed. Lemmen et. al. (2010) and Lemmen (2012) presented conceptual and legal aspects of LADM development, while Lemmen, Van Oosterom and Bennet (2015) examine the motivation, requirements and goals for developing LADM. Paasch et. al. (2015) propose a more detailed classification of the legal part of LADM (i.e. interests in land), than described in the current standard by further developing the LADM's 'right', 'restriction' and 'responsibility' (RRR) class and associated code lists.

According to Paulsson and Paasch (2015), a number of publications describe national implementations of the standard from e.g. technical or registration point of view and are therefore often limited to describing a country's own need for and use of LADM. A reason for this focus may be that researchers are likely more familiar with their own country's needs, potential and problems on implementing the standard. These publications are not only of domestic interest but valuable for other researchers enabling international comparisons of problems and possibilities e.g. concerning how to implement the LADM into one's own legal systems. So, Babalola et. al. (2015) analyses the possibilities of LADM implementation in Nigeria; Elia (2013) proposes the use of LADM as the reference model for the Cyprus land information system; Góźdź and Van Oosteroom (2015) present the case of Poland and 
Ghawana et. al (2018) examine the land administration of Mozambique. Besides, case reports from other countries are available on conference papers and other research publications.

\subsection{The LADM and the Brazilian cadastres}

Since the publication of ISO 19152: 2012, there have been studies on the application of the LADM to the Brazilian land administration situation. The results of some of these works serve as the basis for this proposal of integration.

The urban cadastre was the subject of the research of Santos (2013), in which the viability of applying the LADM to the Brazilian urban cadastre was investigated. Although technical standards or specific legislation for the implementation of urban cadastres do not yet exist in Brazil, the formulated model presents the main classes that are common to many of the systems currently in existence. Considering the open system characteristics proposed, this basic model was found to apply to Brazilian urban cadastres. Paiva (2016) explored the possibility of integrating cadastral data with data from land registries in the LADM.

Frederico (2014) described the cadastres of the public properties of the Union and proposed their integration into a model based on the LADM. Purificação and Carneiro (2017) continued this work, exploring the modelling for the cases of rural properties. Marra (2017) analyzed the application of LADM to land regularization processes, with application to the titling of a Quilombola territory. The author concluded that the LADM offers a conceptual and instrumental reference to coherently represent the relations of ownership and property provided in the Brazilian legislation, using the representation of both formal and informal tenure at different levels.

Costa (2016) and Silva (2017) dealt with the modelling of the third dimension of the cadastre, with Costa (2016) directing her research to the cadastre of apartments and Silva (2017) developing the model for underground water distribution networks.

These studies demonstrated that the flexibility of the ISO19152:2012 LADM applies to the different aspects of the Brazilian cadastre. However, it was still necessary to test the integration of these models, and this is the objective of the present study.

\section{An Integrated Model Proposal for The Brazilian Cadastre}

The fragmentation of the Brazilian cadastres results in difficulty in access to information, duplication and inconsistencies in data and waste of resources. LADM proposes to integrate these systems for multiple users and this research tested its application to the main Brazilian cadastres:

- SNCR: The electronic National Rural Cadastre System was created in 2015 to modernize the Brazilian rural cadastre. It allows owners of rural property to update their data and their properties already registered at the SNCR database through the Electronic Declaration for Cadastre of Rural Property, which includes information on personal data, structure and of usage. It also includes visual information of the property, where available. All rural property is registered in the cadastre, with rural property defined as an area of continuous land, regardless of its location, that has the same landholder (whether the owner or squatter) with agricultural, livestock, extractive, agro-industrial or forestry purposes. This registration is required to obtain the Rural Property Cadastre Certificate (Certificado de Cadastro de Imóvel Rural- CCIR), an essential document for granting agricultural credit, leases, parcellation, sale or promise to sell the rural property.

- SIAPA and SPIUnet: According to the research conducted by Frederico (2014), the SPU has two systems for the cadastre of public property of the Union: the Integrated Property Management (Sistema Integrado de 
Administração Patrimonial- SIAPA) and the Management System of the Special Use of Properties of the Union (Sistema de Gerenciamento de Imóveis de Uso Especial da União - SPIUnet). These cadastres are characterized by being descriptive; that is, there is no cartographic base associated with their data. Initially, the properties were registered according to Article 99 of the Civil Code: dominial properties were registered in the SIAPA, the ones of special use were registered in the SPIUnet, and the ones of common use of the people did not belong to any system. The systems include data relating to these properties, their use, the user, lawsuits, technical data of the land, descriptive memoranda of the land, images, register data, improvement data and of the responsible for the information.

- Urban Cadastre: The urban cadastre in Brazil is not based on specific standards or legislation. It is the responsibility of the Municipalities to implement the cadastre of urban properties and to keep the information updated, generally for tax purposes. Although there are cases of cadastres structured to meet multiple users in public management, most of these still do not present complete coverage of the urban area neither is there coherent or updated information available for land parcels. Data included in the urban cadastre includes the identification of people/institutions and units (urban properties), usage, geometric information (not always based on surveys or cartography) and attributes related to property valuation through mass evaluation.

The proposal of the integrated modelling of these cadastres was developed in three stages:

a) The conceptual modelling of each package, considering its essential attributes, according to the LADM proposal, to guarantee a simple and efficient result that serves multiple users. The integration of the packages results in the integrated cadastre model;

b) The implementation of the conceptual model with the creation of the geographic database through relational tables; and

c) The validation of the model through its application in two real situations, to rural public property and private urban property.

\section{Results}

\subsection{Conceptual modelling according to the LADM}

The development of the conceptual model began with an analysis of the attributes in each cadastre. It was verified that all of them had an excess of information and different standardizations that prevented the systematic exchange of data between the institutions. Only those attributes that were modelled according to the actual requirements of the LADM were considered, to make the proposed system as simple as possible, in order to render its integration viable. The model involves a Party (LA_Party) and a Spatial Unit (LA_SpatialUnit) that are related by Rights, Restrictions, and Responsibilities (LA_RRR).

In this stage of the modelling, the CASE tool OMT-G Design was used, which introduces geographic primitives that increase the semantic representation capacity of the UML (Unified Modelling Language). According to Borges, Davis Jr. and Laender (2005), this tool supports "whole-part" topological structures, network structures, multiple object representations and spatial relations, as well as providing primitives for modelling the geometry and topology of the geographical data. The model also allows for the specification of alphanumeric attributes and methods associated with each class. The main elements include its graphic representations and its codification capacity, because textual annotations are replaced by the design of explicit relations, which denote the dynamics of the interaction between the various spatial and non-spatial objects.

The OMT-G has classes grouped into palettes. The first is of the conventional type, the second is called Field, 
for classes of the geo-field type, the third, Geometry, for geo-objects with geometry and the last, Topology, for geoobjects with geometry and topology.

a) Party Package

This package was modelled with the LA_Party, LA_GroupParty classes and LA_PartyMember association class (see Figure 2), which include the attributes of a person or organization, a group of people or organizations, and the members of a group. Besides, the nationality attributes (namely, Brazilian or foreign) were included in the LA_Party class and the registered address of the person or organization, since the person may not reside in the property. The BR_SPU_Agency class, created by Frederico (2014), came to be called BR_Agency, which represents the inclusion of the administrative body as a party since the institutions (including INCRA, SPU and municipalities) are also related to the spatial unit in terms of rights, restrictions and responsibilities. This class is fundamental in the integration of the cadastres to indicate the responsibility for the corresponding data and includes attributes such as the name and the identifier of the administering agency.

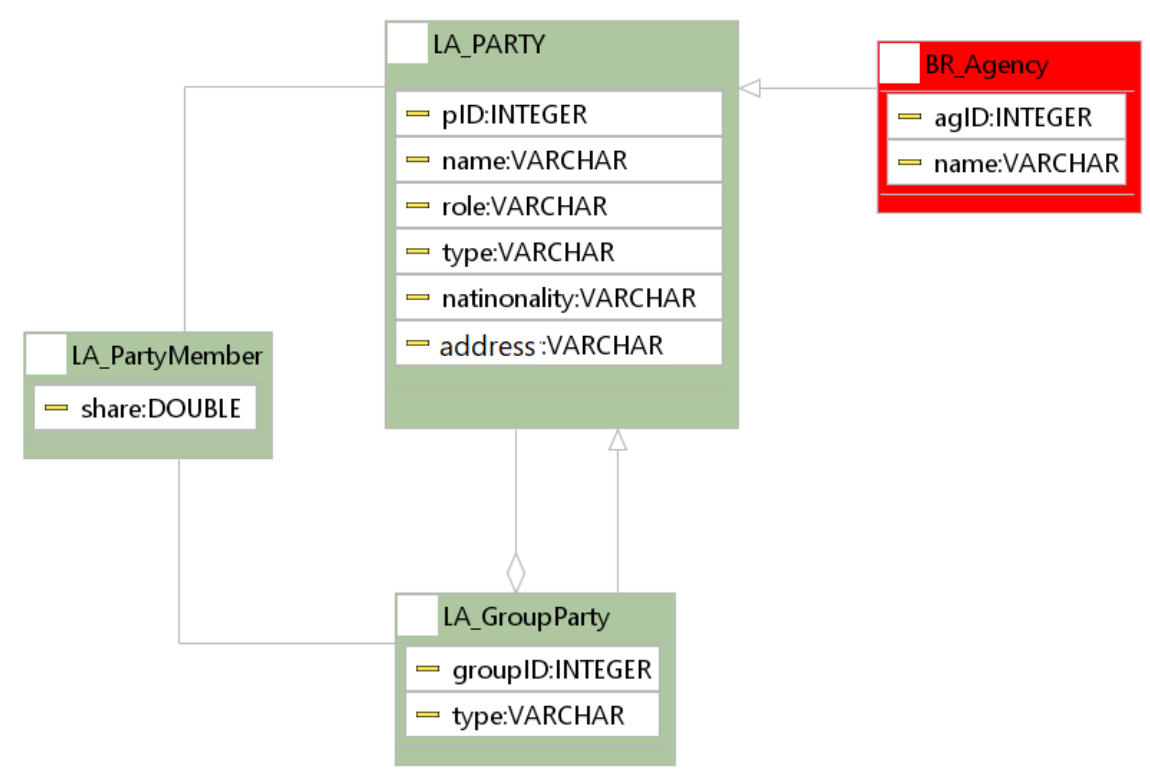

Figure 2: Party Package Modelling.

\section{b) Administrative Package}

In this package, the relationship between people and land is modelled through the LA_Right, LA_Responsibility and LA_Restriction classes, which are specializations of the LA_RRR class (see Figure 3). The LA_BAUnit class includes the administrative units that are required to register basic property units. The BR_BAUnit class was included in the proposal to refer to the basic administrative unit of the land for this modelling, which will integrate rural property, urban property, and property of the Union. It determines that all property must have a unique identifier and include the attribute type, which will identify which type of property is being registered.

In principle, all rights, restrictions, and responsibilities are based on a particular administrative source, as instances of the LA_AdministrativeSource class. The BR_AdministrativeSource has been included to represent the type of administrative data source in Brazil and is related to the BR_Agency. The BR_LandUse class indicates the use of a property and is associated with the LA_Responsibility class, besides having an inheritance relationship with the LA_Restriction class, considering that there may or may not be a value associated with the usage, described in the value attribute. Besides, there may be a rate or fee for the use of the property. Thus, the party may have the responsibility to pay this fee, and its non-payment may prevent the use of the property, constituting a restriction. 
The BR_RightLand class was included in the model to represent the different types of land rights existing in Brazil. The classifications provided under the SNCR were considered (property right, right of tenure and tenure for simple occupation), the direito real de laje (assignment of surface rights above or below a building) for urban properties and other rights about property of the Union.

The BR_Uselnformation refers to the type of usage of a property, describing the types of public properties provided for in article 99 of the Civil Code (common use of the people, special use and dominial use), the uses pertinent to rural properties (agriculture, livestock, beekeeping, etc.) and urban properties (residential, industrial, commercial, etc.).

The BR_Registry class contains information of the real estate registration (notary office, registration number, book and sheet), while the BR_Evaluation class includes attributes relating to the evaluation of the asset, including the attributes value, currency and date (relating to the property valuation), in addition to the BR_Restriction that includes the types of restrictions on use described in the SNCR database.

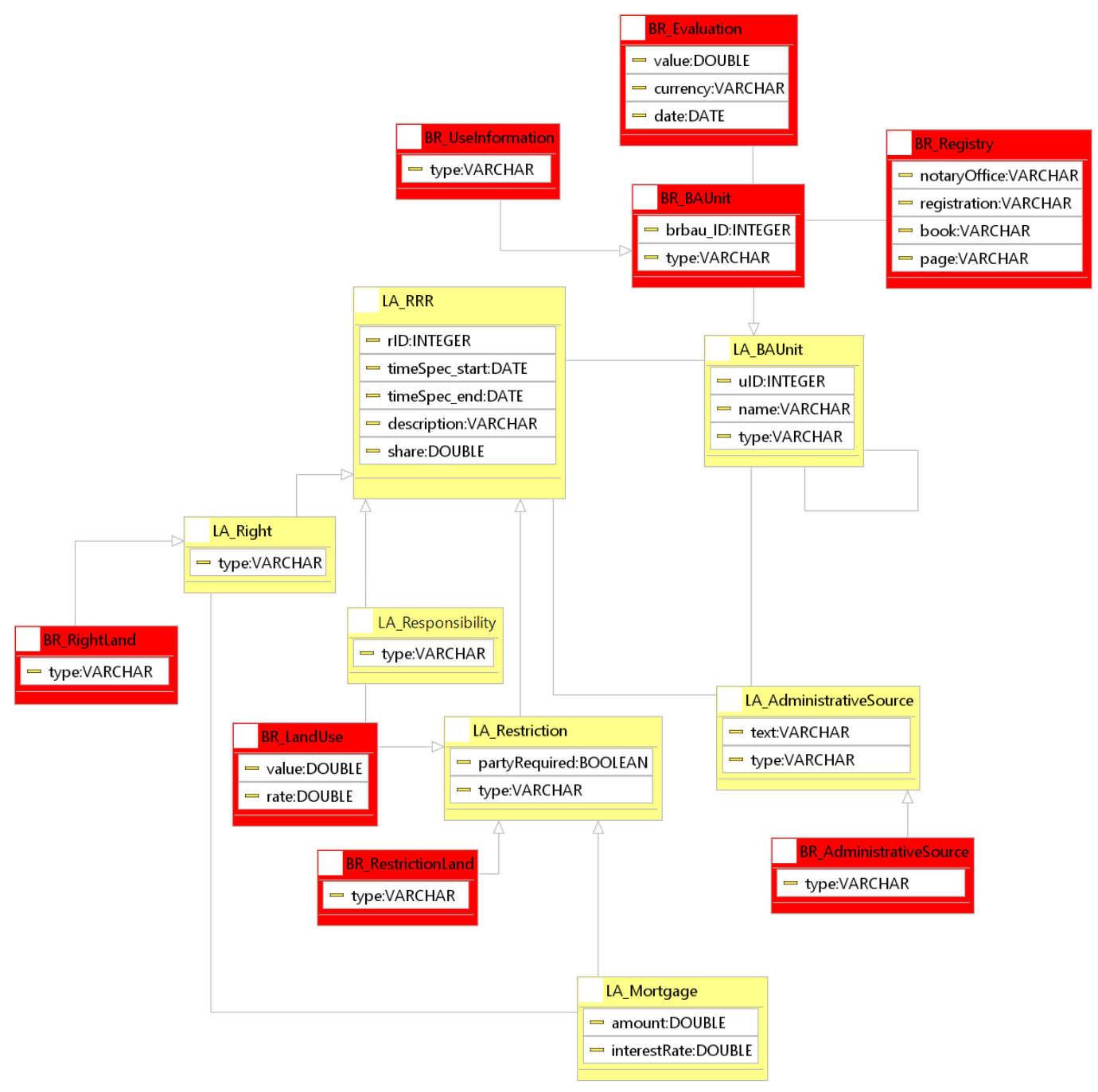

Figure 3: Administrative Package Modelling.

\section{c) SpatialUnit Package}

The result of the modelling of this package is shown in Figure 4. The spatial units (parcels) are described in the LA_SpatialUnit class. Groups of spatial units (condominiums, towns, cities) are described in LA_SpatialUnitGroup. The LA_LegalSpaceBuildingUnit class classifies the types of construction units, with the network structures being described in the LA_LegalSpaceUtilityNetwork class, while the LA_Level class is a collection of spatial units with a 
geometric, topological, and thematic coherence (Lemmen et al., 2015).

d) Surveying and Representation Subpackage

Figure 5 shows the result of this modelling package. The Surveying and Representation Subpackage refers to the geometric representation of the spatial units. In this case, three classes were modelled:

LA_BoundaryFaceString, to set boundaries with 2D lines;

LA_Point, which includes data on the georeferenced points of the spatial unit; and

LA_SpatialSource, which is used as the basis for the historical mapping and reconstitution of the model. This class registers all documentation relating to historical surveys, which may include final surveys (generally formal, such as those certified by INCRA).

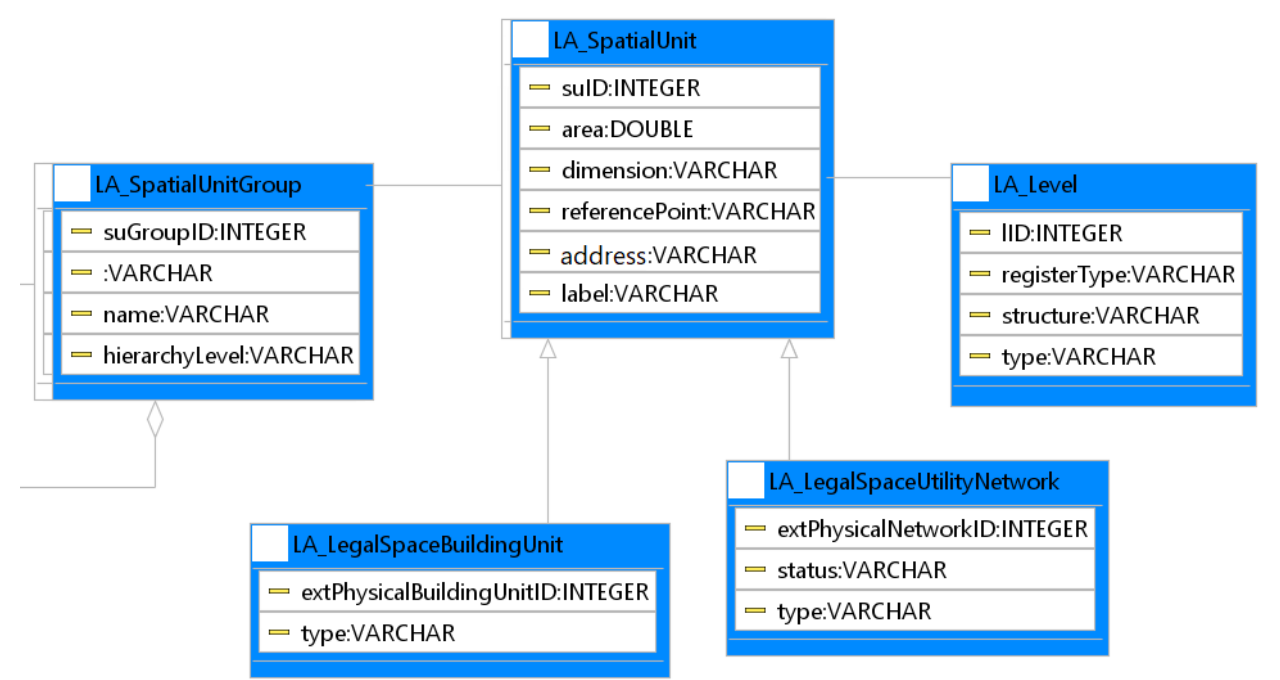

Figure 4: Spatial Unit Package Modelling.

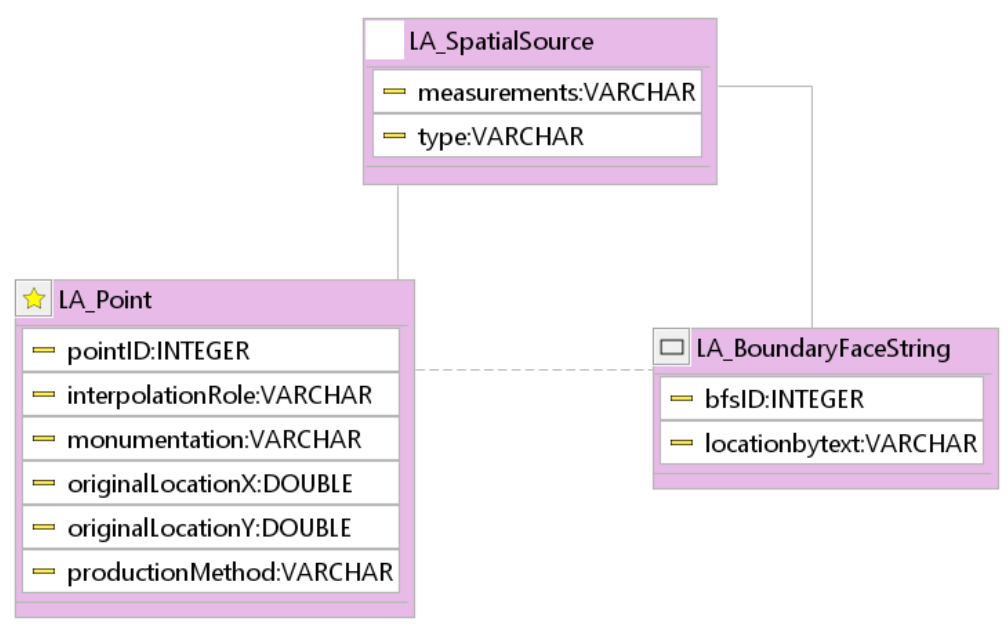

Figure 5: Surveying and Representation Subpackage Modelling.

e) Modelling of the integrated cadastres

After the individual modelling of the packages for each register, the relations between these were identified. The final result is shown in Figure 6, where the classes represented in green correspond to the party package; in yellow, the administrative package; in blue, the spatial unit package; in pink, the subpackage of surveying and representation; and in red, the external classes. 
This model can be considered as a basic module of integrated cadastre, to which other currently existing cadastres can be added, such as the Rural Environmental Cadastre (CAR), the indigenous land cadastre, as well as others that may be created.

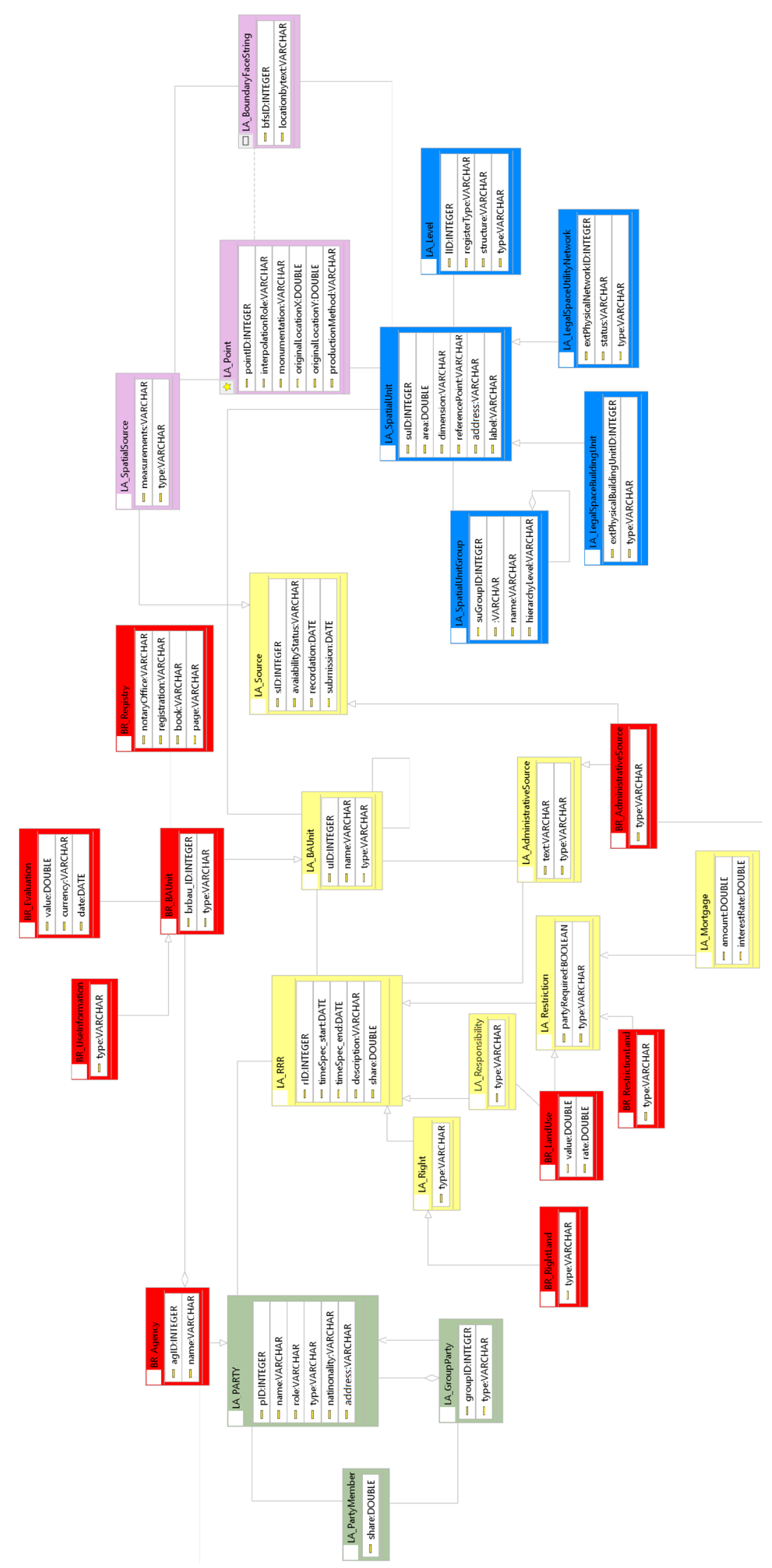

Figure 6: Integrated cadastre model. 


\subsection{Implementation of the conceptual model}

The implementation stage comprises the transformation of the conceptual model into SQL Scripts to create the geographic database through relational tables. For this transformation, three computer tools were tested: OMT-G Design, DB-Designer and MySQL Workbench.

Although it is possible to implement the models with any of these tools, the OMT-G Design was more efficient, for it was able to represent all the types of relations described in the LADM as well asas some types of spatial relationships not provided for in the standard.. The relationship is because this tool was developed specifically for modelling geographic databases, which allows a graphic description and abstraction of all realworld phenomena directly in the conceptual model. Besides, the OMT-G model is currently used as a standard in the geographical data modelling of the Spatial Data Infrastructure (SDI). Use of the tool OMT-G Design makes it possible to apply the specifications of an international standard, which allows for addressing the inconsistencies in concepts, technologies, and applications of various cadastres, and also allows for compliance with the national recommendations for spatial data modelling.

The CASE tool OMT-G Design allows the transformation of the conceptual model into SQL Scripts for the creation of the geographic database through relational tables. The implementation stage consists of this transformation, where the diagrams are exported to the Postgres/PostGIS SQL.

Using the PGAdmin III database manager, the 29 tables defined in the conceptual model were created and are presented in Figure 7.

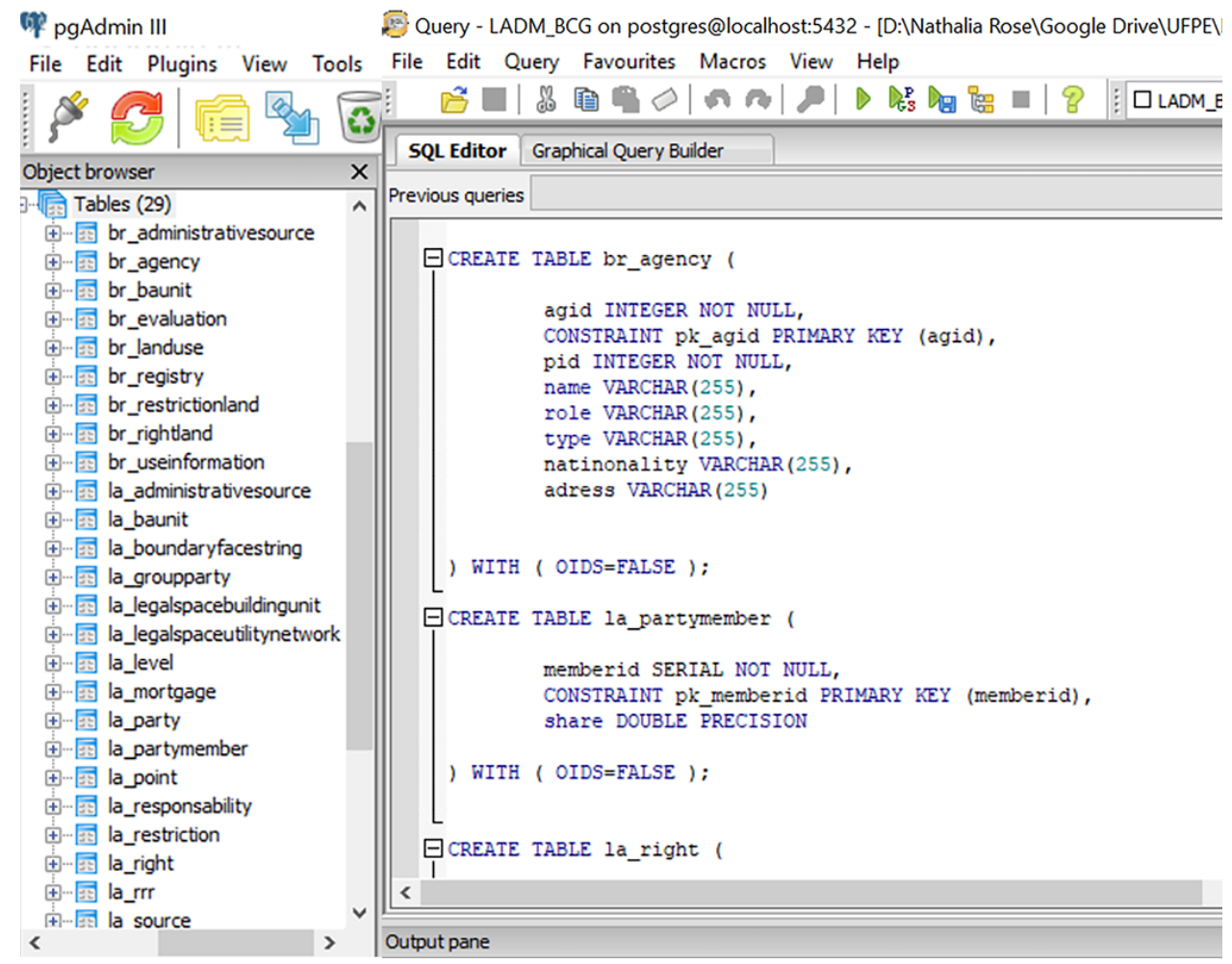

Figure 7: Implementation of the conceptual model using PostgreSQL. 


\subsection{Validation of the model of integrated cadastre proposal}

For the validation of the proposal, the modelling was applied in a case study represented by a real land structure and simulated descriptive data. The graphical data (see Figure 8) were generated by Sousa Neto (2010), describing the land structure of a predominantly rural municipality.

\section{Municipality of Vermelho Bonito}

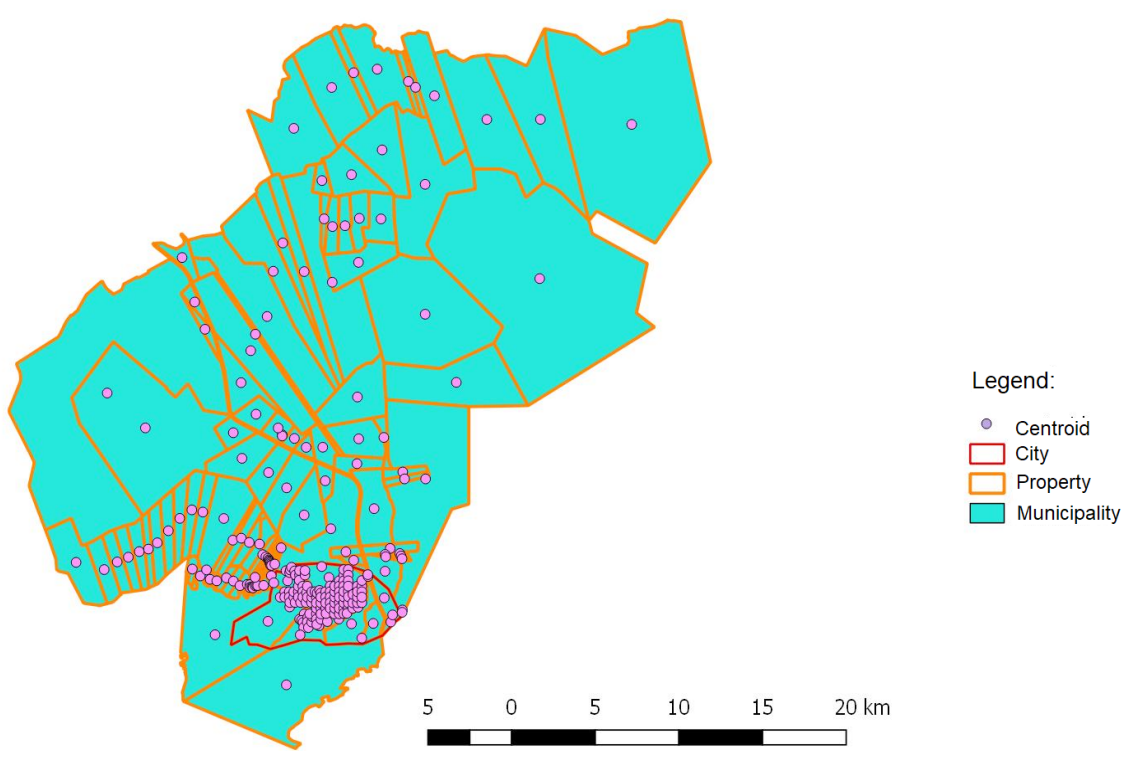

Figure 8: Configuration of the study area used in the validation of the proposal.

The database was manually fed using PGAdmin III, the PostgreSQL administrator since the amount of data used in the test was not extremely large. The same tool allows the import of data via files with CSV extension, thus automating the database feed, which becomes necessary in the application in real cases.

The simulation of the descriptive data (see Figure 9) was elaborated in a way as to represent as accurately as possible some types of relations between people and land involving the managing agencies SPU, INCRA and municipalities.

\begin{tabular}{|c|c|c|c|c|c|c|}
\hline \multicolumn{7}{|c|}{$\begin{array}{l}\square \text { Edit Data - PostgreSQL } 9.5 \text { (localhost:5433) - LADM_omtg_design - public.la_party } \\
\text { File Edit View Tools Help }\end{array}$} \\
\hline$\vdots$ & | 잉》|国| & 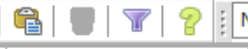 & No limit & & & \\
\hline & $\begin{array}{l}\text { pid } \\
\text { [PK] integer }\end{array}$ & $\begin{array}{l}\text { la_groupparty_groupid } \\
\text { character varying(255) }\end{array}$ & $\begin{array}{l}\text { name } \\
\text { character varying(255) }\end{array}$ & $\begin{array}{l}\text { role } \\
\text { character varying(255) }\end{array}$ & $\begin{array}{l}\text { type } \\
\text { character varying(255) }\end{array}$ & $\begin{array}{l}\text { nationality } \\
\text { character vi }\end{array}$ \\
\hline $\mathbf{1}$ & 104 & 112 & Universidade Federal & & nonNaturalPerson & \\
\hline 2 & 158 & 101 & Public Agency 3 & & nonNaturalPerson & \\
\hline 3 & 178 & 106 & Public Agency 2 & & nonNaturalPerson & \\
\hline 4 & 198 & 107 & Public Agency 1 & & nonNaturalPerson & \\
\hline 5 & 4529024 & 111 & Maria do Rosario Gomes & Farmer & naturalPerson & brasileiro \\
\hline 6 & 7654189 & 123 & Joao Vicente da Silva & Citizien & personNatural & brasileiro \\
\hline 7 & 7665143 & 105 & Henrique de Lemos & Farmer & naturalPerson & brasileiro \\
\hline 8 & 8765098 & 104 & Pedro de Lemos & Farmer & naturalPerson & brasileiro \\
\hline 9 & 156189298 & 103 & Severina de Lemos & Farmer & naturalPerson & brasileiro \\
\hline
\end{tabular}

Figure 9: Descriptive data.

According to Cumbe (2016), the administration of the cadastral database in PostgreSQL is functional from the spatial extension PostGIS, which is capable of storing and processing large volumes of geospatial data. Based on this 
extension, shapefiles were inserted into the columns of classes that have a geometric representation (LA_Point and LA_BoundaryFaceString as shown in Figure 10).

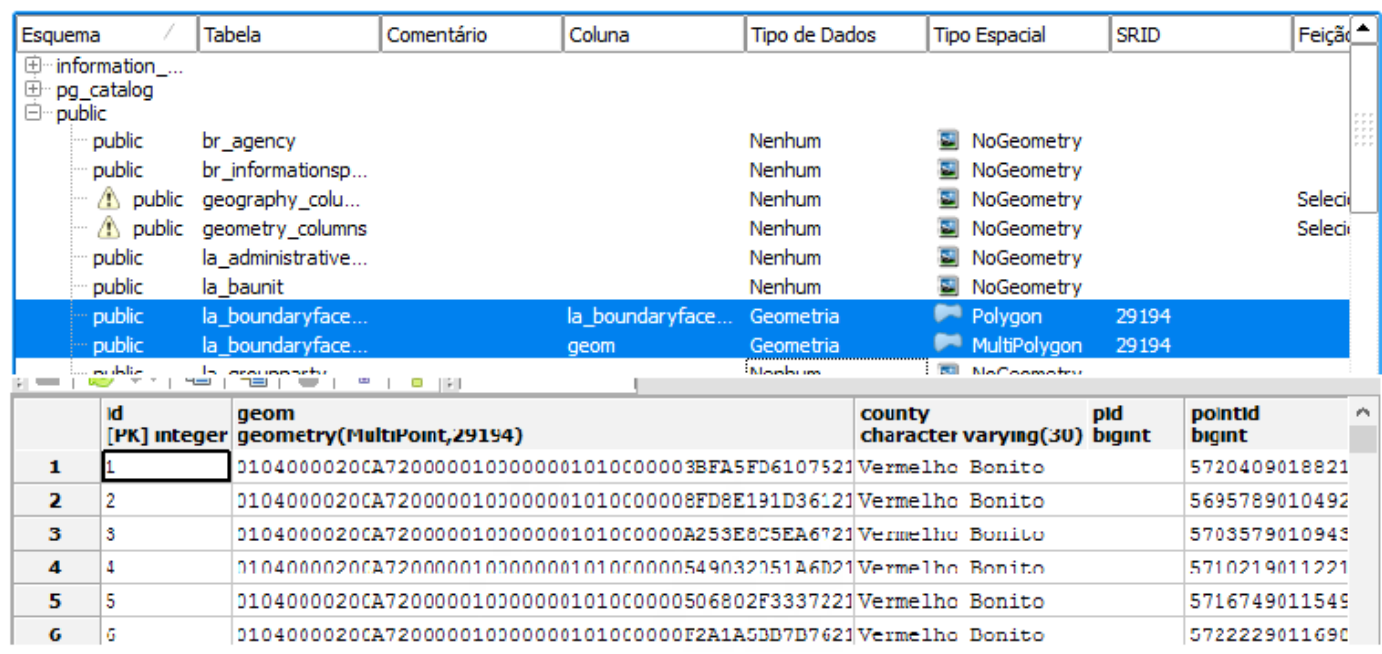

Figure 10: Graphical data associated with the LA point and LA Boundary Face String classes.

After importing the data into the database, information queries were performed with the psql command, which allows the user to execute SQL queries and view their results in the PGAdmin III.

Through the selection of attributes and foreign keys, it is possible to relate different tables. Thus, it is necessary to execute several queries to view all the information of a particular property, which makes the functionality of the model difficult.

However, with the use of the PostGIS spatial extension, it is possible to visualize the graphical property data associated with the descriptive data through the table of attributes in the QGIS program.

To verify the consistency of the proposed model, two situations were chosen. The first concerns a query for a Union property used by a private individual (private use of public property). João Vicente (name of the party) is the tenant (type of right) of a property belonging to the Union, administered by the SPU (name of the agency). A tax of $5 \%$ of the property value is due for its use, which is described in the attribute rate. The real estate parcel is identified by the identifier brbau_id. Figure 11 shows the result of this situation in the database.

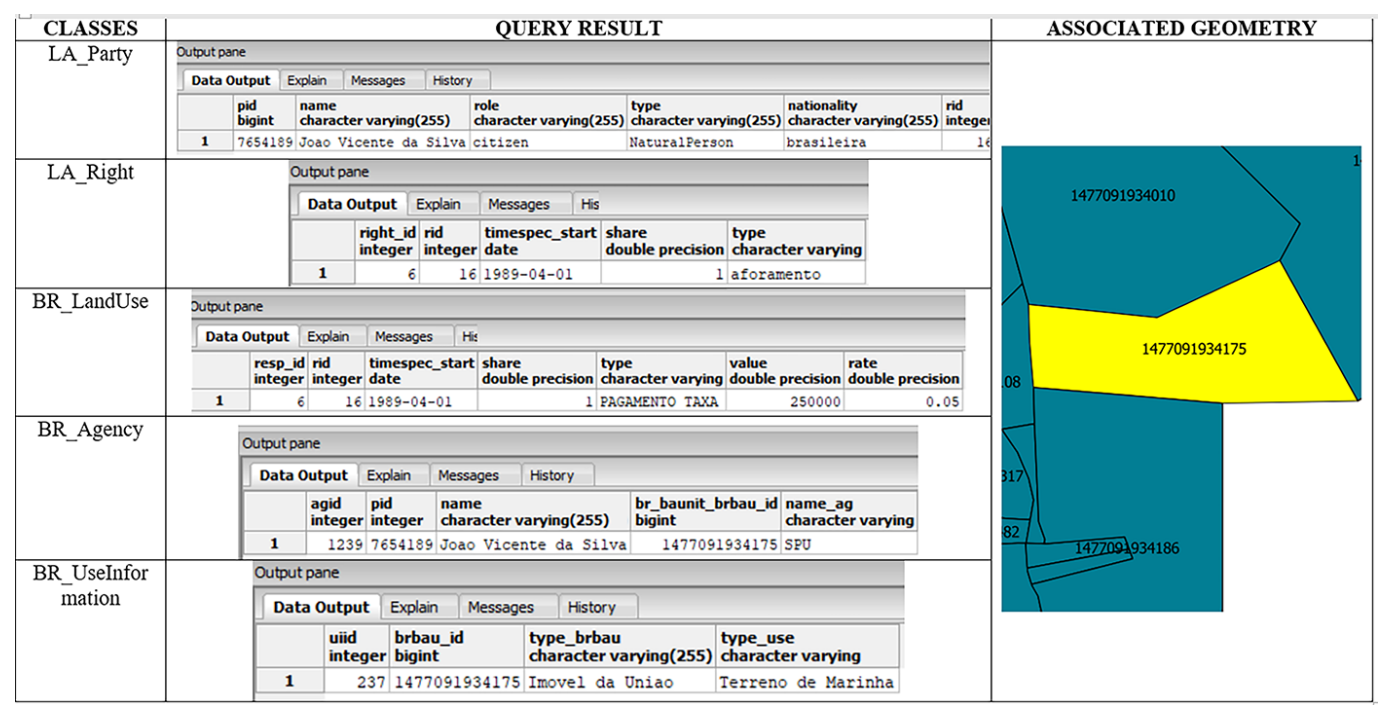

Figure 11: Query of a property of the Union used by a private individual. 
The second situation deals with an urban property belonging to a private owner (see Figure 12). Daniel Antonio de Almeida (name of the party) is the owner (type of right) of an urban real estate parcel for residential use, which is administered by the hypothetical municipality of Vermelho Bonito. The identifier brbau_id identifies the real estate parcel.

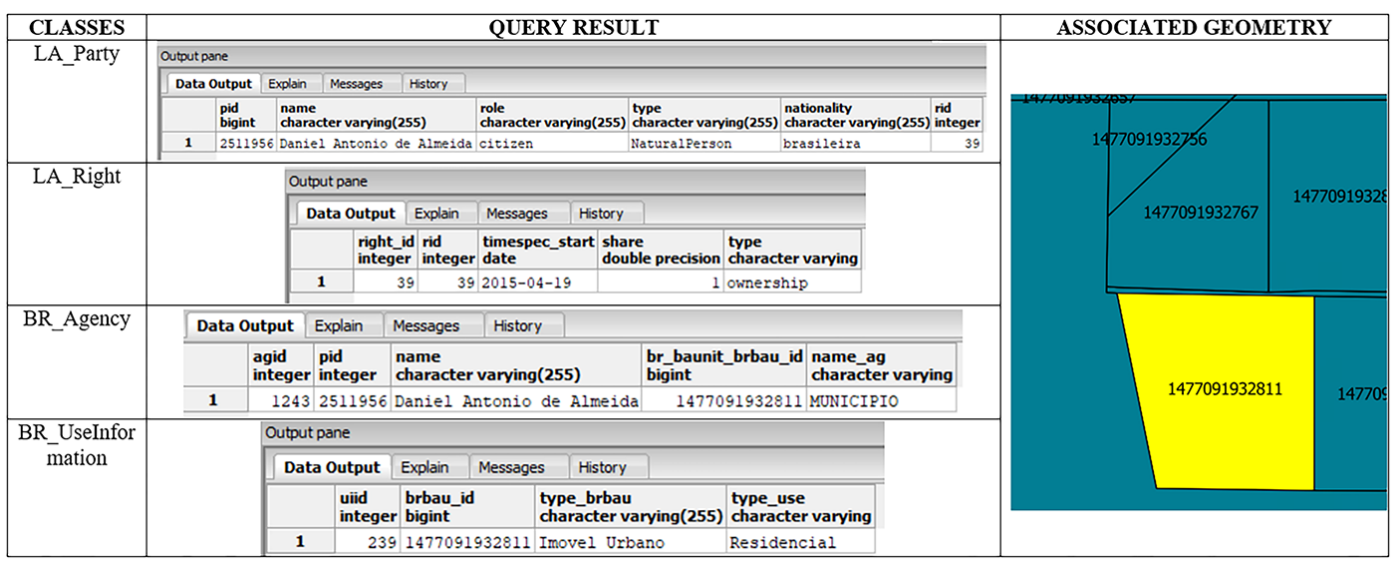

Figure 12: Query of an urban residential property with a private owner.

\subsection{Abstract test suite}

The abstract test suite, described in Annex A of ISO 19.152, verifies if the profile developed for the country conforms to LADM specifications in terms of package and level. For each package or sub-package three levels of compliance are specified: level 1 (low level), level 2 (medium level), and level 3 (high level). A package is level 1 compliant if only level 1 indicator classes are passing the conformance test. A package is level 2 compliant if the both levels 1 and 2 indicator classes are passing the conformance test. A package is level 3 compliant if all levels indicator classes are passing the conformance test.

It is observed in Figure 13 and according to the methods and requirements of each test, that the packages and sub-package implemented for Brazilian cadastres are Level 2 compliance, as they have the required attributes and relationships of dependence of the indicator classes at levels 1 and 2 simultaneously.

\section{Discussions}

The model proposed and implemented in this article used spatial data in shapefile format. Currently the different agencies and institutions managing cadastres have paper data, CAD and a few in GIS formats. To assure systems interoperability it is suggested to standardize this data into shapefile. For this, it is necessary to execute cadastral updates or georeferencing operations for analog maps and the transformation of CAD data into shapefile, considering the current reference system in the country. Due to the huge amount of information these institutions have, this process will be slow and gradual. Besides, the implemented database manages only the active state data, but it is recommended by ISO 19.152:2012 that historical data is kept in the inactive form system.

The profile developed already has some classes compatible with level 3 compliance. However, to reach this level is necessary to consider 3D data (represented in LA_BoundaryFace class), the relationship between the basic administrative units (represented in LA_RequiredRelationshipBAUnit class) and the relationship between the spatial units (represented in the class LA_RequiredRelationshipSpatialUnit). 


\begin{tabular}{|c|c|c|c|}
\hline LADM package & LADM class & $\mathrm{Cl}^{\mathrm{a}}$ & Dependencies \\
\hline \multirow[t]{2}{*}{-} & VersionedObject & 1 & \\
\hline & LA_Source & 1 & $\begin{array}{l}\text { Oid, LA_AdministrativeSource (as a minimum, this } \\
\text { specialization must be implemented) }\end{array}$ \\
\hline \multirow[t]{4}{*}{ Party Package } & & & Exist only if Administrative Package is implemented \\
\hline & LA_Party & 1 & VersionedObject, Oid, LA_PartyType \\
\hline & LA_GroupParty & 2 & VersionedObject, Oid, LA_Party, LA_GroupPartyType \\
\hline & LA_PartyMember & 2 & VersionedObject, LA_Party, LA_GroupParty \\
\hline \multirow{9}{*}{$\begin{array}{l}\text { Administrative } \\
\text { Package }\end{array}$} & & & Exist only if Party Package is implemented \\
\hline & LA_RRR & 1 & $\begin{array}{l}\text { VersionedObject, Oid, LA_Party, LA_BAUnit, LA_Right } \\
\text { (as a minimum, this specialization shall be } \\
\text { implemented), LA_AdministrativeSource }\end{array}$ \\
\hline & LA_Right & 1 & LA_RRR, LA_RightType \\
\hline & LA_Restriction & 2 & LA_RRR, LA_RestrictionType \\
\hline & LA_Responsibility & 3 & LA_RRR, LA_ResponsibilityType \\
\hline & LA_BAUnit & 1 & VersionedObject, Oid, LA_RRR, LA_BAUnitType \\
\hline & LA_Mortgage & 2 & LA_Restriction \\
\hline & LA_AdministrativeSource & 1 & $\begin{array}{l}\text { LA_Source, LA_Party, LA_AdministrativeSourceType, } \\
\text { LA_AvailabilityStatusType }\end{array}$ \\
\hline & LA_RequiredRelationshipBAUnit & 3 & VersionedObject, LA_BAUnit \\
\hline \multicolumn{4}{|l|}{$\begin{array}{l}\text { Spatial Unit } \\
\text { Package }\end{array}$} \\
\hline & LA_SpatialUnit & 1 & VersionedObject, Oid, LA_SpatialSource \\
\hline & LA_SpatialUnitGroup & 2 & VersionedObject, Oid, LA_SpatialUnit \\
\hline & LA_LegalSpaceBuildingUnit & 3 & LA_SpatialUnit \\
\hline & LA_LegalSpaceUtilityNetwork & 3 & LA_SpatialUnit \\
\hline & LA_Level & 2 & VersionedObject, Oid, LA_RegisterType \\
\hline & $\begin{array}{l}\text { LA_RequiredRelationshipSpatialU } \\
\text { nit }\end{array}$ & 3 & VersionedObject, LA_SpatialUnit \\
\hline \multicolumn{4}{|l|}{$\begin{array}{l}\text { Surveying and } \\
\text { Representation } \\
\text { Subpackage }\end{array}$} \\
\hline & LA_Point & 2 & $\begin{array}{l}\text { VersionedObject, Oid, LA_SpatialSource, } \\
\text { LA_PointType, LA_InterpolationType }\end{array}$ \\
\hline & LA_SpatialSource & 2 & $\begin{array}{l}\text { LA_Source, LA_Point, LA_Party, LA_SpatialUnit } \\
\text { (unless it is changed), LA_SpatialSourceType }\end{array}$ \\
\hline & LA_BoundaryFaceString & 2 & VersionedObject, Oid, LA_Point (if using geometry) \\
\hline & LA_BoundaryFace & 3 & VersionedObject, Oid, LA_Point (if using geometry) \\
\hline
\end{tabular}

Figure 13: The LADM conformance requirements table.

Source: ISO/FDIS 19.152 (2012).

\section{Conclusions}

The results of the research demonstrated the viability of the integration of the different land cadastres found in Brazil through the use of the LADM model. For this, it was necessary to identify, among the many attributes found in these cadastres, those attributes essential to a simple system that meets the needs of multiple end-users.

Considering the flexibility of the model, which allows for the inclusion of new classes according to changing end-user needs, LADM can be the primary module to be used in the structuring of SINTER (National System of Management of Land Information), which provides for the integration of cadastres and Brazilian land registries. 
The work evaluated the suitability of the OMT-G Design tool in the implementation of the conceptual model. In general, the use of the tool did not present great difficulties. The generated SQL script is compatible with PostgreSQL, so the only changes made were to modify the order of the creation of the tables that had foreign keys, and the attributes of the type Double that were modified for Double Precision. Besides, the PostGreSQL does not accept attribute names of distinct classes referenced as primary keys with the same name.

For future work, it is recommended to include in the model the temporal question, with the definition of classes related to the maintenance of the history of the changes occurred.

\section{ACKNOWLEDGEMENT}

The authors acknowledge the CNPq - National Research Council, for the Scientific Initiation Grant; the FACEPE Foundation for Research Support in the state of Pernambuco, for financing the Project APQ-0167-1.07/15; and all those involved in the LADM modeling proposals for Brazilian cadastres.

\section{AUTHOR'S CONTRIBUTION}

Conceptualization: Purificação, N. R. S. and Carneiro, A.F.T.;

Data collect: Purificação, N. R. S.;

Modeling and Implementation: Purificação, N. R. S;

Review and supervision: Carneiro, A.F.T. e Julião, R. P.;

Discussion of results: Purificação, N. R. S.

\section{References}

Alkan, M., and Comert, C., 2010. A design of temporal geographic information systems (TGIS) for Turkish land register and cadastre data. Scientific research and essays, 5 (7), 700-708.

Aydinoglu, A.C., and Inan, H.I., 2014. Developing land registry and cadastre base data model for land management applications. FIG Congress 2014, 16-21 June 2014 Kuala Lumpur, Malaysia.

Babalola, S.O., Abdul Rahman, A., Choon, L. T. and Van Oosterom, P. 2015. Possibilities of land administration domain model (LADM) implementation in Nigeria. ISPRS annals of the photogrammetry, remote sensing and spatial information sciences, Volume II-2/W2.

Borges, K. A. V., Davis Jr., C. A., Laender, A. H. F. 2005. Modelagem Conceitual de Dados Geográficos. In: Casanova, M. A., Câmara, G., Davis Jr., C. A., Vinhas, L., Queiroz, G. R. (Eds.) Bancos de Dados Geográficos. Curitiba (PR): EspaçoGeo. Ch.3.

Carneiro, A. F. T. 2003. Cadastro Imobiliário e Registro de Imóveis: A Lei N. 10.267/2001, Decreto N. 4.449/2002 2 Atos Normativos do INCRA. Porto Alegre: Sérgio Antônio Fabris Editor.

Comert, C., and Alkan, M., 2004. The design and development of a temporal GIS for cadastral and land title data of Turkey. International society of photogrammetry and remote sensing, XXth Congress, 12-23 July i stanbul, Turkey.

Cumbe, R. A. 2016. Modelo De Implementação De Cadastros Territoriais Multifinalitários Urbanos Em Moçambique. 
Dissertação. Universidade Federal de Pernambuco.

Doner, F., and Biyik, C., 2013. Conformity of LADM for modeling 3D/4D cadastre situations in Turkey. 5th land administration domain model workshop, 24-25 September 2013, Kuala Lumpur, Malaysia.

Elia, E.A., Zevenbergen, J. A., Lemmen, C. and Van Oosterom, P. 2013. The land administration domain model (LADM) as the reference model for the Cyprus land information system (CLIS). Survey review, 45 (329), 100-110.

Frederico, L.N.S. 2014. Modelagem de Cadastro Territorial Multifinalitário de Bens Imóveis da União de acordo com a LADM ISO/FDIS 19152/2012. Dissertação. Universidade Federal de Pernambuco.

Góźdź, K.J., and van Oosterom, P.J.M., 2015. Developing the information infrastructure based on LADM - the case of Poland. Survey Review, 48 (348), 168-180. DOI:10.1179/1752270615Y.0000000018.

Ghawana, T., Cumbe, R., Hespanha, J. P., Paixao, S. and Carneiro, A. F. T. 2018. Applicability of knowledge innovation value chain model for the land administration system of municipality of Maputo in Mozambique, Survey Review, DOI: $10.1080 / 00396265.2018 .1554852$.

ISO, 2012. ISO 19152:2012, Geographic Information - Land Administration Domain Model, edition 1. ISO, Geneva, Switzerland, $118 \mathrm{p}$.

Lemmen, C., Oosteron, P. Van. and Bennett, R.M. 2015. The Land Administration Domain Model. Land Use Policy, v.49, pp. 535-545, DOI: 10.1016/j.landusepol.2015.01.014.

Lemmen, C.H.J., 2012. A domain model for land administration. PhD thesis. Technische Universiteit Delft the Netherland.

Lemmen, C.H.J., van Oosteron, P., Eisenhut, C. And Uitermark, H. 2010. The modelling of rights, restrictions and responsibilities (RRR) in the land administration domain model (LADM). FIG Congress 2010 facing the challenges building the capacity, 11-16 April Sydney, Australia.

Paasch, J.M., Van Oosterom, P., Lemmen, C. and Paulsson, J. 2015. Further modelling of LADM's rights, restrictions and responsibilities (RRRs). Land use policy, 49, 680-689.

Paulsson, J. and Paasch, J. M. 2015. The Land Administration Domain Model - A literature Survey. Land Use Policy, v.49, pp. 546-551, DOI: 10.1016/j.landusepol.2015.08.008.

Polat, Z. A., Alkan, M., van Oosterom, P. J. M. and Lemmen, C. H. J. 2018. A LADM-based temporal cadastral information system for modelling of easement rights. Survey Review, DOI: 10.1080/00396265.2018.1503481.

Purificação, N. R. S.; Carneiro, A. F. T. 2017. Teste e Validação de Metodologias para Implementação de Modelos de Cadastro Territorial de Acordo com a ISO 19.152. In: XXV Conic - Congresso de Iniciação Científica da Universidade Federal de Pernambuco.

Santos, J. C. 2012. Análise da Aplicação do Modelo de Domínio de Administração Territorial ao Cadastro Territorial Urbano Brasileiro. Dissertação. Universidade Federal de Pernambuco.

Sousa Neto, J. A. 2010. Análise da Estruturação do Cadastro Nacional de Imóveis Rurais - CNIR com Vistas a sua Integração à Infraestrutura Nacional de Dados Espaciais - INDE. Dissertação. Universidade Federal de Pernambuco.

UN/ECE, 1996. Land Administration Guidelines. With Special Reference to Countries in Transition. United Nations/ Economic Commission for Europe, Geneva, Switzerland, 112p.

UN-GGIM. 2019. Framework for Effective Land Administration: A reference for developing, reforming, renewing, strengthening or modernizing land administration and management systems. United Nations Committee of Experts on Global Geospatial Information Management (UN-GGIM). Available at: <http://ggim.un.org/meetings/GGIMcommittee/9th-Session/documents/E_C.20_2020_10_Add_1_LAM_background.pdf >.

van Oosterom, P.J.M., and Lemmen, C.H.J., 2015. The land administration domain model (LADM): Motivation, standardisation, application and further development. Land use policy, 49, 527-534, DOI: 10.1016/j. landusepol.2015.09.032. 
van Oosterom, P.J.M., Ploeger, H., Stoter, J., Thompson, R. And Lemmen, C. 2006. Aspects of a 4D cadastre: a first exploration. XXIII FIG Congress, TS 14-3D and 4D Cadastres, October 8-13 Munich, Germany.

van Oosterom, P.J.M., and Lemmen, C., 2002. Impact analysis of recent geo-ICT developments on cadastral systems. XXII FIG Congress, Washington, DC, USA.

Williamson, I., Enemark, S., Wallace, J. and Rajabifard, A. 2010. Land Administration for Sustainable Development Esri Press, 380 New York Street, Redlands, California 92373-8100. 